"Comprehensive Comparison of a Current-Source and a Voltage-Source Converter for Three-Phase EV Fast Battery Chargers"

IEEE CPE International Conference on Compatibility and Power Electronics, Lisboa Portugal, pp.173-178, June 2015.

http://ieeexplore.ieee.org/stamp/stamp.jsp?tp=\&arnumber=7231068

ISBN: 978-1-4799-6300-3

DOI 10.1109/CPE.2015.7231068

This material is posted here with permission of the IEEE. Such permission of the IEEE does not in any way imply IEEE endorsement of any of Group of Energy and Power Electronics, University of Minho, products or services. Internal or personal use of this material is permitted. However, permission to reprint/republish this material for advertising or promotional purposes or for creating new collective works for resale or redistribution must be obtained from the IEEE by writing to pubs-permissions@ieee.org. By choosing to view this document, you agree to all provisions of the copyright laws protecting it.

(C) 2015 IEEE 


\title{
Comprehensive Comparison of a Current-Source and a Voltage-Source Converter for Three-Phase EV Fast Battery Chargers
}

\author{
Vítor Monteiro, J. G. Pinto, Bruno Exposto, João L. Afonso \\ ALGORITMI Research Centre - University of Minho, Guimarães - Portugal \\ \{vitor.monteiro | gabriel.pinto | bruno.exposto | joao.1.afonso\}@algoritmi.uminho.pt
}

\begin{abstract}
This paper presents a comprehensive comparison of a current-source converter and a voltage-source converter for three-phase electric vehicle (EV) fast battery chargers. Taking into account that the current-source converter (CSC) is a natural buck-type converter, the output voltage can assume a wide range of values, which varies between zero and the maximum instantaneous value of the power grid phase-to-phase voltage. On the other hand, taking into account that the voltage-source converter (VSC) is a natural boost-type converter, the output voltage is always greater than the maximum instantaneous value of the power grid phase-to-phase voltage, and consequently, it is necessary to use a dc-dc buck-type converter for applications as EV fast battery chargers. Along the paper is described in detail the principle of operation of both the CSC and the VSC for EV fast chargers, as well as the main equations of the power theory and current control strategies. The comparison between both converters is mainly established in terms of the total harmonic distortion of the grid current and the estimated efficiency for a range of operation between $10 \mathrm{~kW}$ and $50 \mathrm{~kW}$.
\end{abstract}

Keywords-EV Battery Charger; Current-Source Converter; Voltage-Source Converter.

\section{INTRODUCTION}

Nowadays, the electric vehicle (EV) is seen as new paradigm in the transport sector, which is fundamental to reduce the greenhouse gases emissions and for contributing to a more sustainable and efficient mobility [1]. Nevertheless, to the power grids, the EV is seen as a new substantial load that must be introduced without jeopardize the power quality [2] neither the power grid stability [3]. In order to perform the EV battery charging process from the power grid are required on-board or off-board EV battery chargers to transform ac voltages and currents into dc [4][5]. The on-board EV battery charger is installed inside the EV and can be used to plug the EV directly to the power grid. Typically, the power level of on-board chargers is below $6.6 \mathrm{~kW}$ and are identified in the literature as slow chargers [6][4]. The off-board EV battery chargers are installed outside the EV in specific charging places, and are used to deliver power directly to the EV batteries, i.e., the power converter (ac-dc) is outside the EV [7][8]. Off-board chargers are identified in the literature as fast chargers and typically present power levels above $50 \mathrm{~kW}$. Using bidirectional EV battery chargers it is also possible deliver part of the energy stored in the batteries back to the power grid. This operation mode is identified in the literature as vehicle-to-grid (V2G) and is common with on-board EV battery chargers. The off-board EV battery chargers are used to charge the batteries as fast as possible. Therefore, it is not relevant the bidirectional operation mode, i.e., interrupt the charging process to deliver energy to the power grid. In [9] is presented a study about the pro and cons of the on-board and off-board systems. Typically, both EV battery charging systems (on-board and off-board) are composed by two power stages: one ac-dc to interface the power grid followed by a dc-dc to interface the batteries [10][11]. Independently of the EV battery charging system, it is important to obtain sinusoidal current and unitary power factor in the ac side, and controlled voltage and current in the dc side. These features are used to preserve the power quality and to accomplish with the battery charging requirements

In order to contribute to the dissemination of technologies for EV battery chargers, this paper presents a comprehensive comparison of two off-board EV fast battery chargers. This comparison is established between two three-phase three-level converters, one based in a current-source converter (CSC) and other in a voltage-source converter (VSC). It is assumed that they are connected to the power grid in a three-phase system of phase-to-phase rms voltages of $400 \mathrm{~V} 50 \mathrm{~Hz}$ and that the minimum and maximum power is, respectively, $10 \mathrm{~kW}$ and $50 \mathrm{~kW}$. Fig. 1 shows the circuit topology of the two EV fast battery chargers under comparison. Fig. 1(a) shows an EV fast battery charger based in a CSC, which is composed by a single power stage: an ac-dc three-phase three-level CSC. Taking into account that the CSC is a buck-type converter, the output voltage can assume a wide range of values, which varies between zero and the maximum instantaneous value of the phase-to-phase power grid voltage. Therefore, it is not necessary use a dc-dc back-end converter. Moreover, using a $\mathrm{CSC}$ it is also possible control the grid current in order to obtain sine wave currents shapes in phase with the power grid fundamental voltage positive sequence. Fig. 1(b) shows an EV fast battery charger based in a VSC, which is composed by two power stages: an ac-dc three-phase three-level VSC, and a dc-dc back-end converter. Taking into account that the VSC is a boost-type converter, the output voltage assumes a wide range of values, but always greater than the maximum instantaneous value of the phase-to-phase power grid voltage. Therefore, it is necessary use a dc-dc back-end buck-type converter to adjust the dc-link voltage to a level appropriate to charge the batteries (typically, the nominal voltage in the batteries is below than $560 \mathrm{~V}$, which is the maximum instantaneous value of the phase-to-phase voltage). This is the main drawback of this converter compared with the CSC. In 

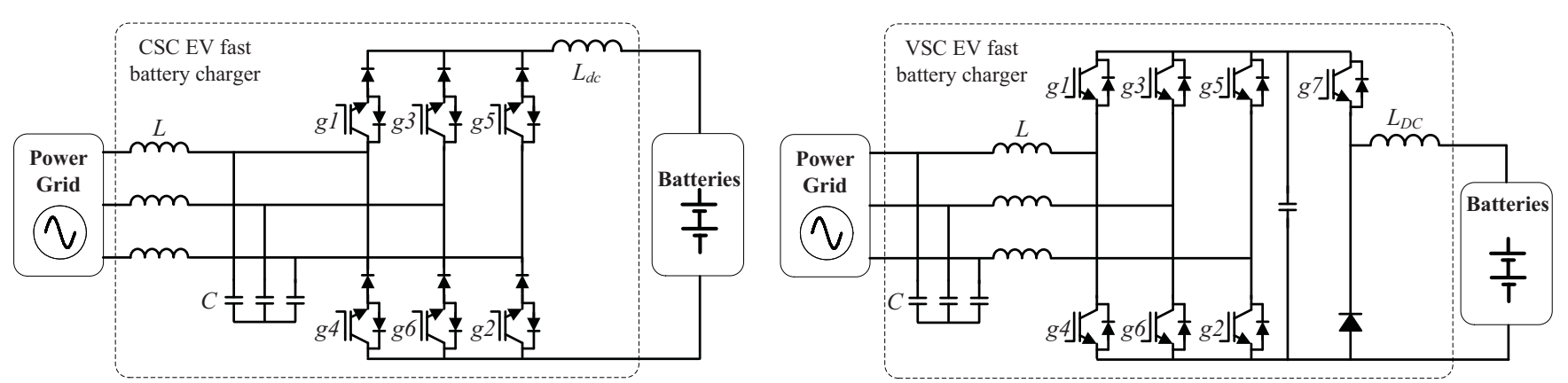

Fig. 1. Circuit topologies of the EV fast battery chargers in comparison: (a) Based in a CSC; (b) Based in a VSC.

order to perform a typical EV fast battery charging process, the output voltage varies between $300 \mathrm{~V}$ and $450 \mathrm{~V}$. Using a VSC it is also possible control the grid current in order to obtain sine wave currents in phase with the power grid fundamental voltage positive sequence. In section II is presented the design of the controller power theory for the two EV fast battery chargers. Therefore, in this section are described in detail the main steps that allow obtain the grid current references for both CSC and VSC. In section III is presented the current control strategies for the two EV fast battery chargers, i.e., the main steps that allow synthetize the current or voltage references for the CSC and VSC, respectively. In section IV is established a comparison in terms of the estimated efficiency of the two three-phase three-level converters (CSC and VSC) for EV fast battery chargers, rated for $50 \mathrm{~kW}$ and designed using commercial components. Finally, section V presents the main conclusions.

\section{EV FAST BATtery CHARGER CONTROLLER DESIGN}

In this section is presented the power theory that allows obtain the grid current references for the EV battery chargers based in a CSC and in a VSC. In order to simplify the power theory description, it is assumed that the power grid voltage is composed only by the fundamental component. However, it is important to refer that in the digital controller is used a phase-locked loop (PLL) algorithm, allowing to obtain sinusoidal references to the grid current. In the scope of this paper, it was used the three-phase PLL implemented in $\alpha \beta$ coordinates $(\alpha \beta$-PLL) proposed in [12]. Considering that the single-phase power grid voltage $\left(v_{g}\right)$ and the single-phase grid current $\left(i_{g}\right)$ are expressed, respectively, by:

$$
\begin{gathered}
v_{g}=\sqrt{2} V_{g} \operatorname{sen}(\omega t), \\
i_{g}=\sqrt{2} I_{g} \operatorname{sen}(\omega t+\varphi),
\end{gathered}
$$

the three-phase active power $\left(P_{g}\right)$ can be defined by:

$$
\begin{gathered}
P_{g}=V_{g a} I_{g a} \cos \left(\varphi_{a}\right)+V_{g b} I_{g b} \cos \left(\varphi_{b}\right)+ \\
+V_{g c} I_{g c} \cos \left(\varphi_{c}\right) .
\end{gathered}
$$

Considering that is only transferred active power from the power grid to the batteries, the power grid voltage $\left(v_{g}\right)$ and the grid current $\left(i_{g}\right)$ are in phase, i.e., $\cos (\varphi)=1$. Therefore, considering a balanced system of voltages, from (3) it can be defined an equivalent single-phase conductance $(G)$ according to:

$$
G=\frac{P_{g}}{3 V_{g}^{2}}
$$

where, $V_{g}$ corresponds to the rms value of each single-phase power grid voltage $\left(v_{g a}, v_{g b}\right.$ and $\left.v_{g c}\right)$. Using the conductance defined in (4), the single-phase instantaneous grid current reference for each phase can be defined by:

$$
i_{g i}{ }^{*}=G p l l_{i} \sqrt{2} V_{g i},
$$

where, $p l l$ is the output signal of the $\alpha \beta$-PLL algorithm and $i=a$, $b, c$. For the CSC, neglecting the operation losses, the active power $P_{g}$ corresponds to the power to charge the batteries. Therefore, substituting (4) in (5) is obtained:

$$
i_{g i}{ }^{*}=\frac{V_{B A T} I_{D C}}{3 V_{g}^{2}} p l l_{i} \sqrt{2} V_{g i},
$$

where, the current in the dc-link inductance $\left(I_{D C}\right)$ is controlled through a PI controller. For the VSC, neglecting the losses, the active power $P_{g}$ can be separately in two terms corresponding, respectively, to the power to maintain constant the dc-link voltage $\left(V_{D C}\right)$ and the power to charge the batteries. Therefore, substituting (4) in (5) is obtained:

$$
i_{g}{ }^{*}=\frac{P_{D C}+V_{B A T} I_{B A T}}{3 V_{g}^{2}} p l l_{i} \sqrt{2} V_{g},
$$

where, $P_{D C}$ is obtained from a PI controller. The current to charge the batteries $\left(I_{B A T}\right)$ is controlled by the dc-dc buck-type converter. Therefore, the voltage that this converter must produce $\left(v_{d c-d c}\right)$ to control the batteries current is obtained according with:

$$
v_{d c-d c}=V_{B A T}+L_{D C} f_{S}\left(I_{B A T}^{*}-I_{B A T}\right) \text {. }
$$

\section{EV FAST BATTERY CHARGER: CURRENT CONTROL DESIGN}

In this section are presented the current control strategies for both CSC and VSC EV fast battery chargers. For the CSC, the current control strategy allows synthetize the current references [13][14], and for the VSC allows synthetize the voltage references[15][16].

\section{A. Current Control Strategy of the Current-Source Converter}

Fig. 2 shows the single-phase equivalent circuit of the EV fast battery charger based in the CSC, where are represented the main currents and voltages. This equivalent circuit is used to describe the circuit equations. In order to prevent resonance due to the LC filter, it was used a damping resistor of $10 \Omega$ in parallel with the L filter. From Fig. 2 it can be established that:

$$
\begin{gathered}
i_{g}=i_{r}+i_{l}=i_{c}+i_{C S C}, \\
v_{g}=v_{l}+v_{c} .
\end{gathered}
$$




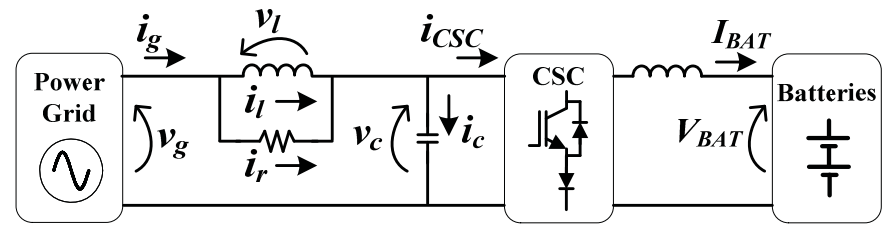

Fig. 2. Circuit topology of the EV fast battery charger based in a CSC.

Taking into account that $i_{r} \ll i_{l}$, it can be assumed that $i_{g} \approx i_{l}$ without introduce significant error to the circuit analysis. Substituting the current in the capacitor $\left(i_{c}\right)$ represented in (9) by the time derivative of its voltage multiplied by its capacitance, it can be established:

$$
i_{g}=\mathrm{C} \frac{d v_{c}}{d t}+i_{C S C} \text {. }
$$

Substituting (10) in (11) and rearranging in order to the current $\left(i_{C S C}\right)$ that the CSC must produce is obtained:

$$
i_{C S C}=i_{g}-C \frac{d v_{g}}{d t}+C \frac{d v_{l}}{d t} .
$$

Finally, substituting the voltage in the inductor $\left(v_{l}\right)$ by the time derivative of its current multiplied by its inductance, it can be established:

$$
i_{C S C}=i_{g}-\mathrm{C} \frac{d v_{g}}{d t}+\mathrm{CL} \frac{d^{2} i_{g}}{d t^{2}} .
$$

Taking into account that it is used a digital controller, the derivative of the power grid voltage $\left(v_{g}\right)$ in (13) can be substituted by its discrete implementation using the forward Euler method according to:

$$
\frac{d v_{g}}{d t}=\frac{v_{g}[k+1]-v_{g}[k]}{T_{s}},
$$

where $v_{g}[k]$ is the actual sample and $v_{g}[k+1]$ is the future sample of the grid voltage and $T_{s}$ is the sampling period. The second order derivative of the power grid current in (13) can be substituted by its discrete implementation defined as:

$$
\frac{d^{2} i_{g}}{d t^{2}}=\frac{i_{g}[k+1]-2 i_{g}[k]+i_{g}[k-1]}{T_{s}{ }^{2}} .
$$

Using (14) and (15), the discrete implementation of (13) results in:

$$
\begin{aligned}
& i_{C S C}[k]=i_{g}[\mathrm{k}]-\mathrm{C} f_{S}\left(v_{g}[k+1]-v_{g}[k]\right)+ \\
& +\mathrm{CL}_{S}^{2}\left(i_{g}[k+1]-2 i_{g}[k]+i_{g}[k-1]\right),
\end{aligned}
$$

where, $f_{s}$ is the sampling frequency. The purpose of this control law is make the error between the grid current $\left(i_{g}\right)$ and its reference $\left(i_{g}{ }^{*}\right)$ equal to zero at the instant $k+1$. Therefore, (16) can be rewritten for:

$$
\begin{gathered}
i_{C S C}[k]=i_{g}[\mathrm{k}]-\mathrm{C} f_{S}\left(v_{g}[k+1]-v_{g}[k]\right)+ \\
+\mathrm{CL} f_{S}{ }^{2}\left(i_{g}{ }^{*}[k]-2 i_{g}[k]+i_{g}[k-1]\right) .
\end{gathered}
$$

In order to compute (17) it is necessary to know the value of the power grid voltage $\left(v_{g}\right)$ in the instant $k+1$. This value can be obtained from the present and previous values using a Lagrange extrapolation [17], given by:

$$
v_{g}[k+1]=3 v_{g}[k]-3 v_{g}[k-1]+v_{g}[k-2] \text {. }
$$

Substituting (18) in (17) is obtained the final current control law that allows control the current produced by the CSC. The

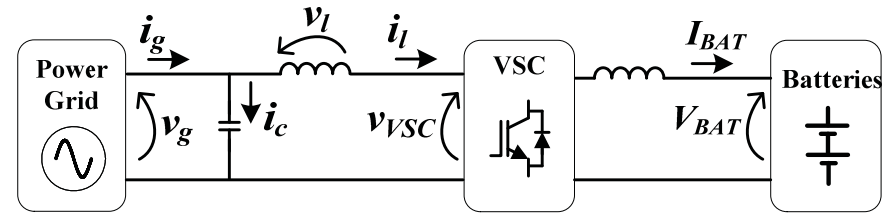

Fig. 3. Circuit topology of the EV fast battery charger based in a VSC.

current $i_{C S C}[k]$ is the reference that is used in the modulator circuit to control the state of the CSC IGBTs. The gate pulse patterns that allow synthesize this current are obtained from a combinational logic circuit [18], which is responsible to generate the CSC valid states. The input of the combinational logic circuit is the result of the comparison between the current $i_{C S C}[k]$ and a pulse-width modulator (PWM) with $20 \mathrm{kHz}$ center-aligned triangular carrier.

\section{B. Current Control Strategy of the Voltage-Source Converter}

Fig. 3 shows the single-phase equivalent circuit of the EV fast battery charger based in the VSC, where are represented the main currents and voltages. This equivalent circuit is also used to describe the circuit equations in a simple way. From Fig. 3 it can be established that:

$$
\begin{gathered}
i_{g}=i_{c}+i_{l}, \\
v_{g}=v_{l}+v_{V S C} .
\end{gathered}
$$

Substituting the current in the capacitor $\left(i_{c}\right)$ represented in (19) by the time derivative of its voltage multiplied by its capacitance, it can be established:

$$
i_{g}=\mathrm{C} \frac{d v_{g}}{d t}+i_{l} \text {. }
$$

Substituting (19) and (20) in (21) and rearranging in order to the voltage $\left(v_{C S C}\right)$ that the VSC must produce is obtained:

$$
v_{C S C}=v_{g}-\mathrm{L} \frac{d i_{g}}{d t}+L C \frac{d^{2} v_{g}}{d t^{2}} .
$$

Using a digital control system, the derivative of the power grid current $\left(i_{g}\right)$ in $(22)$ can be substituted by its discrete implementation using the forward Euler method as aforementioned. Therefore, the discrete implementation of (22) results in:

$$
\begin{aligned}
& v_{C S C}[k]=v_{g}[\mathrm{k}]-\mathrm{L} f_{s}\left(i_{g}[k+1]-i_{g}[k]\right)+ \\
& +\operatorname{CL} f_{S}^{2}\left(v_{g}[k+1]-2 v_{g}[k]+v_{g}[k-1]\right),
\end{aligned}
$$

where, $f_{s}$ is the sampling frequency. The purpose of this control law is make the error between the grid current $\left(i_{g}\right)$ and its reference $\left(i_{g}{ }^{*}[k]\right)$ at instant $k$ equal to zero at time $k+1$. Therefore, (23) can be rewritten for:

$$
\begin{aligned}
& v_{C S C}[k]=v_{g}[\mathrm{k}]-\mathrm{L} f_{s}\left(i_{g}{ }^{*}[k]-i_{g}[k]\right)+ \\
+ & \operatorname{CL} f_{s}^{2}\left(v_{g}[k+1]-2 v_{g}[k]+v_{g}[k-1]\right) .
\end{aligned}
$$

In order to compute (24) it is necessary to know the value of the power grid voltage $\left(v_{g}\right)$ in the instant $k+1$. This value can be obtained as explained for the CSC. Substituting (18) in (24) is obtained the final current control law that allows control the current produced by the VSC. The voltage $v_{C S C}[k]$ is the reference that is used to control the state of the VSC switches. The gate pulse patterns that allow synthesize this voltage are the result of the comparison between the voltage $v_{C S C}[k]$ and a 
TABLE I

SPECIFICATION OF THE EV BATTERY CHARGERS

\begin{tabular}{ccc}
\hline \hline Parameters & Value & Unit \\
\hline Grid Voltage (line-to-line) & $400 \pm 10 \%$ & $\mathrm{~V}$ \\
Output dc Voltage Range & 0 to 500 & $\mathrm{~V}$ \\
Maximum Output Current & 120 & $\mathrm{~A}$ \\
Maximum Output Power & 50 & $\mathrm{~kW}$ \\
\hline Current-Source Converter & \\
\hline Inductor $L$ & 0.5 & $\mathrm{mH}$ \\
Capacitor $C$ & 200 & $\mu \mathrm{F}$ \\
Inductor $L_{D C}$ & 20 & $\mathrm{mH}$ \\
Damping Resistor $R$ & 10 & $\Omega$ \\
\hline Voltage-Source Converter & \\
\hline Inductor $L$ & 3 & $\mathrm{mH}$ \\
Capacitor $C$ & 2 & $\mu \mathrm{F}$ \\
Inductor $L_{D C}$ & 5 & $\mathrm{mH}$ \\
Dc-link Capacitor $C$ & 5 & $\mathrm{mF}$ \\
\hline \hline
\end{tabular}

pulse-width modulator (PWM) with $20 \mathrm{kHz}$ center-aligned triangular carrier.

\section{COMPARION OF EV FAST BATTERY CHARGERS}

In this section are presented some simulation results achieved with PSIM 9.0 software with a time-step of $0.1 \mu \mathrm{s}$. In the simulation model is included the hardware topology, the digital controller, and the battery model. These simulations were performed during the EV fast battery charging process under the conditions of phase-to-phase power grid voltage of $400 \mathrm{~V}$, and with a maximum charging power of $50 \mathrm{~kW}$. In these simulations is considered the EV Nissan Leaf as example of an EV fast battery charging process [11]. Table I shows the specification and key components of the EV fast battery chargers (CSC and VSC).

\section{A. Principle of Operation}

The CSC is used to interface the power grid and the batteries, i.e., it is not required the use of a dc-dc buck-type converter, once the output voltage is always lower than the maximum instantaneous power grid voltage. The CSC is used to maintain the grid current with a sine wave shape and in phase with the power grid voltage, where the amplitude of the grid current is function of the charging current in the dc side. Fig. 4 shows some simulation results of the CSC EV fast battery charger. Fig. 4(a) shows the grid currents $\left(i_{g a}, i_{g b}\right.$ and $\left.i_{g c}\right)$. Fig. $4(\mathrm{~b})$ shows the dc-link current $\left(I_{B A T}\right)$ during a time interval of $100 \mathrm{~ms}$. Fig. 4(c) shows the dc-link current $\left(I_{B A T}\right)$ in function of the line current $\left(i_{g a}\right)$. These simulation results were obtained with a power of $50 \mathrm{~kW}$ and a measured total power factor of 0.99. Fig. 5 shows some simulation results for the phase $a$ during the EV fast battery charging process with a CSC. This figure shows the power grid voltage $\left(v_{g a}\right)$, the grid current $\left(i_{g a}\right)$, and the current produced by the CSC $\left(i_{C S C a}\right)$.

The VSC is used to interface the power grid, however, its output voltage is always greater than the maximum instantaneous power grid phase-to-phase voltage. Therefore, it is necessary use a dc-dc buck-type converter. The ac-dc VSC is used to maintain the grid current with a sine wave shape and in phase with the power grid voltage. This converter is also used to regulate the dc-link voltage where is connected the dc-dc buck-type converter, which is responsible for adjusting the voltage level to charge the batteries. Fig. 6 shows some simulation results of the VSC EV fast battery charger. Fig. 6(a)
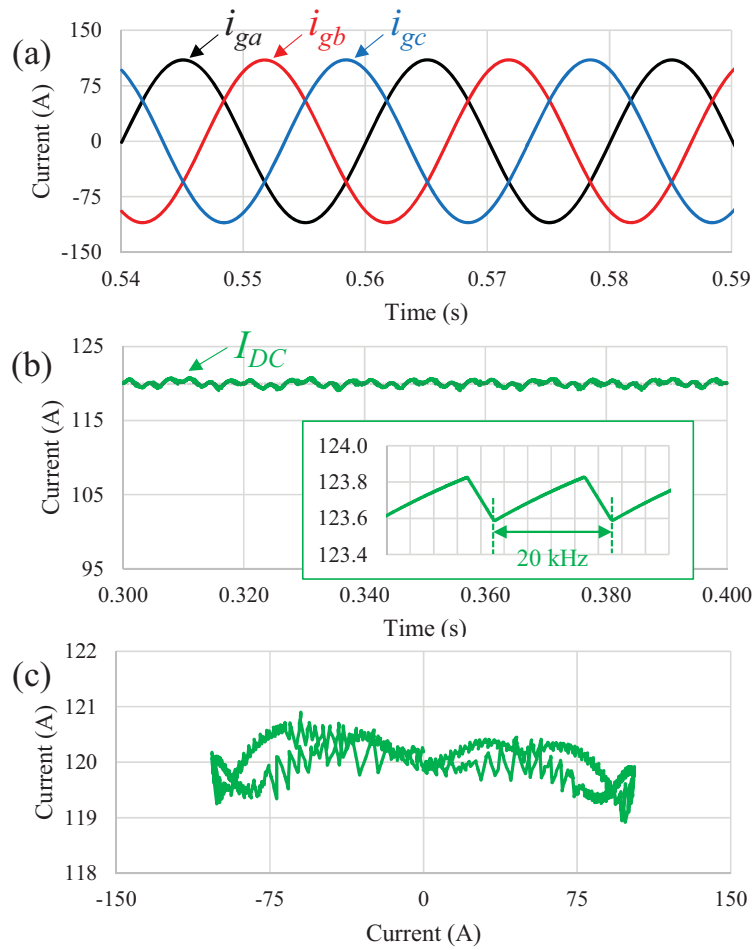

Fig. 4. Simulation resultsof the CSC battery charger: (a) Grid currents ( $i_{g a}, i_{g b}$ and $\left.i_{g c}\right)$; (b) Dc-link current $\left(I_{B A T}\right)$ ripple during a time interval of $100 \mathrm{~ms}$; (c) Dc-link current $\left(I_{B A T}\right)$ in function of the line current $\left(i_{g a}\right)$.

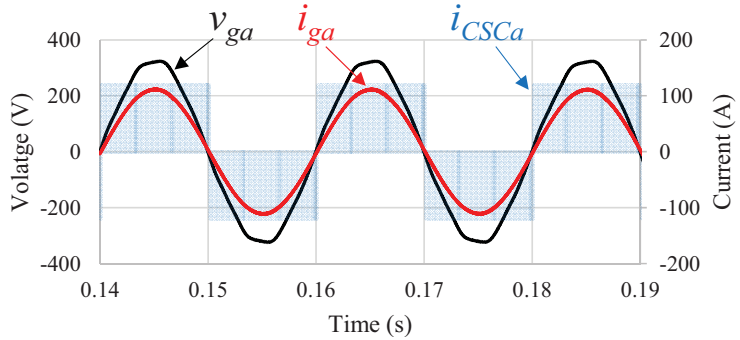

Fig. 5. Simulation results for the phase $a$ during the EV fast battery charging process with the CSC battery charger: Power grid voltage $\left(v_{g a}\right)$; Grid current $\left(i_{g a}\right)$; Current produced by the CSC $\left(i_{C S C a}\right)$.

shows the grid currents $\left(i_{g a}, i_{g b}\right.$ and $\left.i_{g c}\right)$. Fig. 6(b) shows the dc link current $\left(I_{B A T}\right)$ during a time interval of $100 \mathrm{~ms}$. Fig. 6(c) shows the current $\left(I_{B A T}\right)$ in function of the line current $\left(i_{g a}\right)$. Fig. 7 shows some simulation results for the phase $a$ during the EV fast battery charging process with a VSC. This figure shows the power grid voltage $\left(v_{g a}\right)$, the grid current $\left(i_{g a}\right)$, and the voltage produced by the VSC $\left(v_{V S C a b}\right)$. It is important to refer that the voltage produced by the VSC is measured between the phases $a$ and $b$, i.e., the voltage $v_{V S C a b}$. As show in Fig. 4(a) and Fig. 6(a), due to the power theory (cf. section III A) and the grid current control strategy (cf. section III B), the grid current $\left(i_{g a}\right)$ is sinusoidal with low harmonic distortion. However, taking into account that the charging power varies during the battery charging process, the grid current total harmonic distortion (THDi\%) also varies. Fig. 8 shows the grid current $\mathrm{THDi} \%$ in function of the charging power (with a variation between $10 \mathrm{~kW}$ and $50 \mathrm{~kW}$, which corresponds to different points of operation during an EV fast battery charging process). Fig. 9 shows the dc-link current $\left(I_{B A T}\right)$ during a complete EV fast battery charging process. The charging process starts with a current value of $120 \mathrm{~A}$ during almost 4 

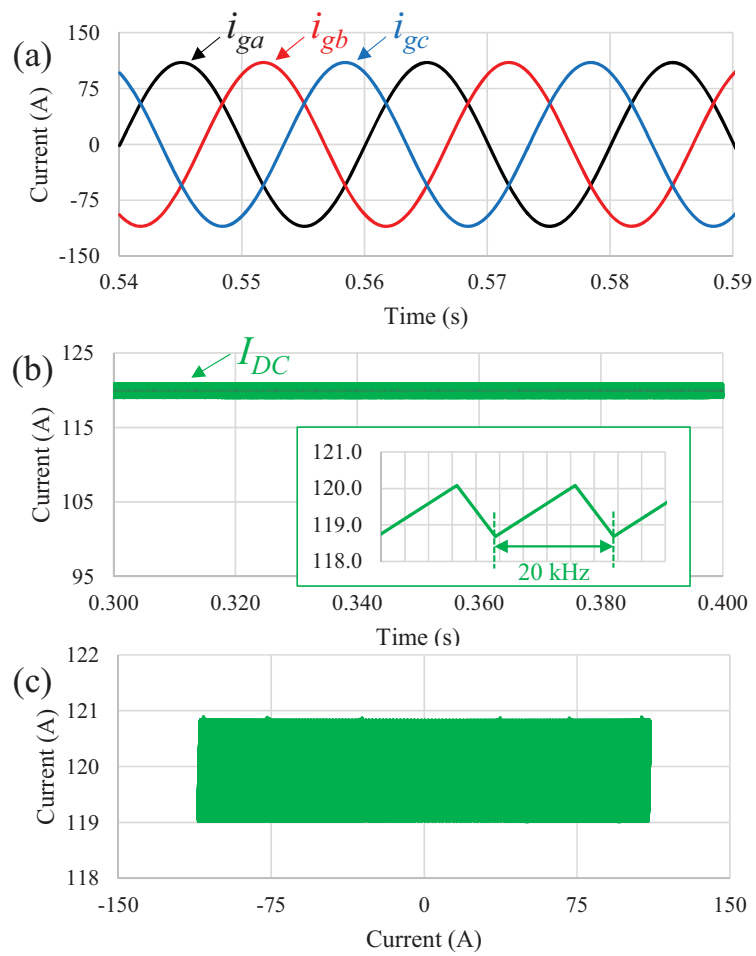

Fig. 6. Simulation results of the VSC battery charger: (a) Grid currents $\left(i_{g a}, i_{g b}\right.$ and $i_{g c}$; (b) Dc-link current $\left(I_{B A T}\right)$ ripple during a time interval of $100 \mathrm{~ms}$; (c) Dc-link current $\left(I_{B A T}\right)$ in function of the line current $\left(i_{g a}\right)$.

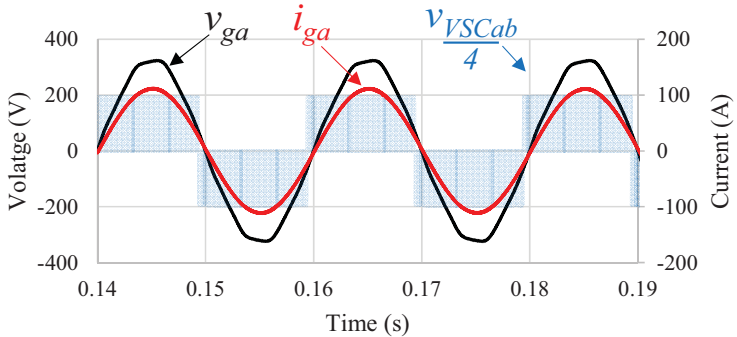

Fig. 7. Simulation results for the phase $a$ during the EV fast battery charging process with the VSC battery charger: Power grid voltage $\left(v_{g a}\right)$; Grid current $\left(i_{g a}\right)$; Voltage produced by the VSC (vCSCab).

minutes. The battery charging process is interrupted when the battery state-of-charge reaches $80 \%$. This situation occurs when the charging current decreases to $30 \mathrm{~A}$. The time required to perform the battery charging was 30 minutes.

\section{B. Estimated Efficiency Comparison}

In this item is established a comparison of the CSC and the VSC EV fast battery chargers in terms of estimated operation efficiency. This comparison was performed using the thermal module of the software PSIM. The thermal module considers the dynamic behavior of real semiconductors towards estimating switching and conduction losses. For the CSC, besides the components specified in Table I, in the simulation model were considered three modules of IGBTs (each one with two IGBTs) from the manufacturer Semikron (model SKM200GB125D) with nominal values of $160 \mathrm{~A}\left(T_{\text {case }}=80{ }^{\circ} \mathrm{C}\right)$ and $1200 \mathrm{~V}$, and six discrete diodes also from the manufacturer Semikron (model SKKE162/12) with nominal values of $160 \mathrm{~A}$ $\left(T_{\text {case }}=95^{\circ} \mathrm{C}\right)$ and $1200 \mathrm{~V}$. For the VSC, besides the components shown in Table I, in the simulation model were considered four modules of IGBTs (each one with two IGBTs)

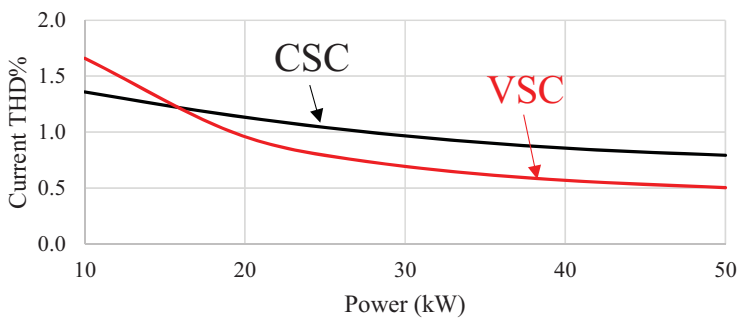

Fig. 8. Comparison of the current THDi\% in function of the charging power for the EV fast battery chargers based in a CSC and a VSC.

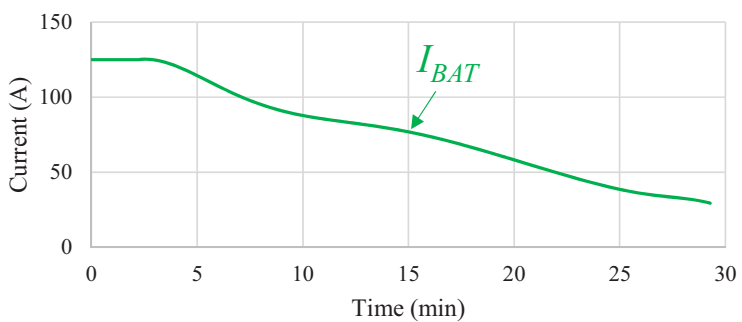

Fig. 9. Battery charging current $\left(I_{B A T}\right)$ during a complete EV fast battery charging process.

from the manufacturer Semikron (model SKM200GB125D) with nominal values of $160 \mathrm{~A}\left(T_{\text {case }}=80{ }^{\circ} \mathrm{C}\right)$ and $1200 \mathrm{~V}$. It is important to refer that the bottom IGBT of the fourth module is not used, i.e., it is only used the reverse diode for the proper operation as buck-type converter. Fig. 10 shows the estimated efficiency of the two EV fast battery chargers for three different operating conditions, namely, $10 \mathrm{~kW}, 30 \mathrm{~kW}$, and $50 \mathrm{~kW}$. As it can be seen, the maximum estimated efficiency $(95.7 \%)$ occurs at the power of $10 \mathrm{~kW}$ using the CSC EV fast battery charger. It is also important to refer that for the three different operating conditions the CSC is always more efficient than the VSC. For the CSC and VSC, Fig. 11 and Fig. 12 shows, respectively, a comparison (in percentage) of the losses distribution for the power operating conditions of $10 \mathrm{~kW}$, $30 \mathrm{~kW}$, and $50 \mathrm{~kW}$. For this comparison were considered the losses in the semiconductors (estimating conduction and switching losses), and in the input and output passive filters.

\section{CONCLUSION}

This paper presents a comprehensive comparison between a current-source converter (CSC) and a voltage-source converter (VSC) for applications in electric vehicle (EV) fast battery chargers. The CSC and the VSC are described in detail along the paper. For both converters is presented the principle of operation and the main equations of the power control theory and the current control strategies. Finally, is presented an efficiency comparison in terms of the total harmonic distortion of the grid current and the estimated efficiency for the operating conditions of $10 \mathrm{~kW}, 30 \mathrm{~kW}$, and $50 \mathrm{~kW}$. This comparison was performed using the thermal module of the software PSIM. The obtained results shows that the total harmonic distortion (THDi\%) of the grid current is lower using a CSC for powers above $15 \mathrm{~kW}$. Using a CSC the maximum estimated efficiency is $95.7 \%$ for a power of $10 \mathrm{~kW}$ and using a VSC is $91.9 \%$ for a power of $30 \mathrm{~kW}$. The results shows that the CSC presents higher estimated efficiency for the different operating conditions. The obtained results also show that the estimated losses are higher in the semiconductors and lower in the input filters. 


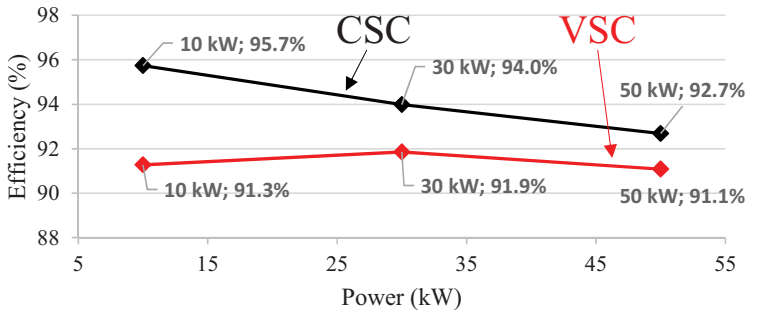

Fig. 10. Estimated efficiency of the two EV fast battery chargers for three different operating conditions $(10 \mathrm{~kW}, 30 \mathrm{~kW}$, and $50 \mathrm{~kW})$.

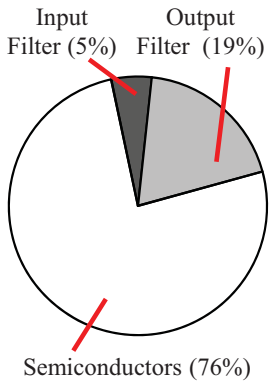

(a) $10 \mathrm{~kW}$
Input Output

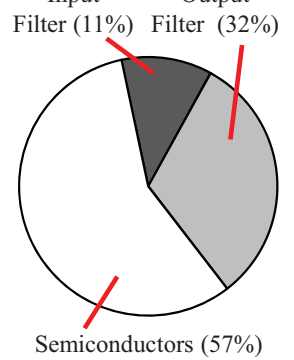

(b) $30 \mathrm{~kW}$

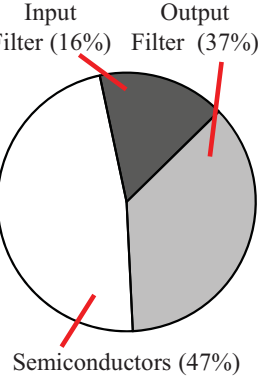

(c) $50 \mathrm{~kW}$
Fig. 11. Estimated losses distribution of the EV fast battery charger based in CSC for diferent operating contitions: (a) $10 \mathrm{~kW}$; (b) $30 \mathrm{~kW}$; (c) $50 \mathrm{~kW}$.

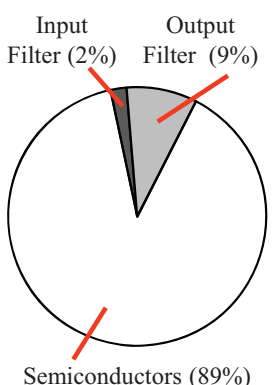

(a) $10 \mathrm{~kW}$

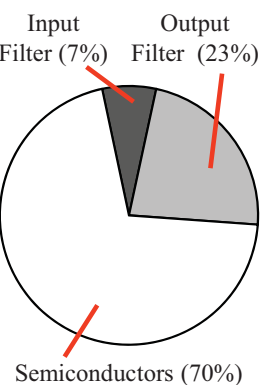

(b) $30 \mathrm{~kW}$
Input Output

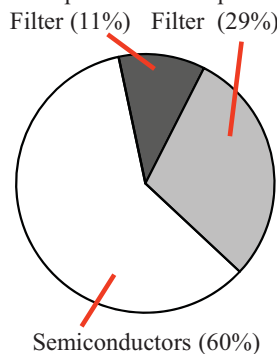

(c) $50 \mathrm{~kW}$
Fig. 12. Estimated losses distribution of the EV fast battery charger based in VSC for diferent operating contitions of: (a) $10 \mathrm{~kW}$; (b) $30 \mathrm{~kW}$; (c) $50 \mathrm{~kW}$.

\section{ACKNOWLEDGMENT}

This work has been supported by FCT - Fundação para a Ciência e Tecnologia in the scope of the project: PEstUID/CEC/00319/2013. Mr. Vítor Monteiro was supported by the doctoral scholarship SFRH/BD/80155/2011 granted by the FCT agency.

\section{REFERENCES}

[1] Kaushik Rajashekara, "Present Status and Future Trends in Electric Vehicle Propulsion Technologies," IEEE J. Emerg. Sel. Topics Power Electron., vol.1, no.1, pp.3-10, Mar. 2013.

[2] Paul S. Moses, Sara Deilami, Amir S. Masoum, Mohammad A. S. Masoum, "Power Quality of Smart Grids with Plug-in Electric Vehicles Considering Battery Charging Profile," IEEE Innovative Smart Grid Technologies Conference Europe, pp.1-7, Oct. 2010.

[3] Farzad Rajaei Salmasi, "Control Strategies for Hybrid Electric Vehicles: Evolution, Classification, Comparison, and Future Trends," IEEE Trans. Veh. Technol., vol.56, no.5, pp.2393-2404, Sept. 2007.
[4] Deepak S. Gautam, Fariborz Musavi, Murray Edington, Wilson Eberle, William G. Dunford, "An Automotive Onboard 3.3-kW Battery Charger for PHEV Application," IEEE Trans. Veh. Technol., vol.61, no.8, pp.3466-3474, Oct. 2012.

[5] J. G. Pinto, Vítor Monteiro, Henrique Gonçalves, João L. Afonso, "Onboard Reconfigurable Battery Charger for ElectricVehiclesWith Traction-to-Auxiliary Mode," IEEE Trans. Veh. Technol., vol.63, no.3, pp.1104-1116, Mar. 2014.

[6] Jun-Young Lee, Hyung-Jun Chae, "6.6-kW Onboard Charger Design Using DCM PFC ConverterWith HarmonicModulation Technique and Two-Stage DC/DC Converter," IEEE Trans. Ind. Electron., vol.61, no.3, pp.1243-1252, Mar. 2014.

[7] Shyh-Jier Huang, Bo-Ge Huang, Fu-Sheng Pai, "Fast Charge Strategy Based on the Characterization and Evaluation of LiFePO4 Batteries," IEEE Trans. Power Electron., vol.28, no.4, pp.1555-1562, Apr. 2013.

[8] Jung-Hyo Lee, Jung-Song Moon, Yong-Seok Lee, Young-Real Kim, Chung-Yuen Won, "Fast Charging Technique for EV Battery Charger using three-phase AC-DC Boost Converter," IEEE IECON Industrial Electronics Society Annual Conference, pp.4577-4582, Nov. 2011.

[9] Charles Botsford, Adam Szczepanek, "Fast Charging vs. Slow Charging: Pros and Cons for the New Age of Electric Vehicles," EVS24 International Battery, Hybrid and Fuel Cell Electric Vehicle Symposium, pp.1-9, May 2009.

[10] T. Soeiro, T. Friedli, J. W. Kolar, "Three-Phase High Power Factor Mains Interface Concepts for Electric Vehicle Battery Charging Systems," IEEE APEC Applied Power Electronics Conference and Exposition, pp.2603-2610, Feb. 2012.

[11] Sanzhong Bai, Srdjan M. Lukic, "Unified Active Filter and Energy Storage System for an MWElectric Vehicle Charging Station," IEEE Trans. Power Electron., vol.28, no.12, pp.5793-5803, Dec. 2013.

[12] Luís Guilherme Barbosa Rolim, Diogo Rodrigues Costa, Maurício Aredes, "Analysis and Software Implementation of a Robust Synchronizing PLL Circuit Based on the pq Theory," IEEE Trans. Ind. Electron., vol.53, no.6, pp.1919-1926, Dec. 2006.

[13] I. Lizama, J. Rodríguez, B. Wu, P. Correa, M. Rivera, M. Pérez, "Predictive Control for Current Source Rectifiers Operating at Low Switching Frequency," IEEE IPMEC International Power Electronics and Motion Control, pp. 1630-1633, May 2009.

[14] P. Zavala, M. Rivera, S. Kouro, J. Rodriguez, B. Wu, V. Yaramasu, C. Baier, J. Munoz, J. Espinoza, P. Melin, "Predictive Control of a Current Source Rectifier with Imposed Sinusoidal Input Currents," IEEE IECON Industrial Electronics Society, Vienna Austria, pp. 5842-5847, Nov. 2013.

[15] Patricio Cortés, Gabriel Ortiz, Juan I. Yuz, José Rodríguez, Sergio Vazquez, Leopoldo G. Franquelo, "Model Predictive Control of an Inverter With Output LC Filter for UPS Applications," IEEE Trans. Ind. Electron., vol.56, no.6, pp.1875-1883, June 2009.

[16] Patricio Cortés, José Rodríguez, “Three-Phase Inverter with Output LC Filter Using Predictive Control for UPS Applications," IEEE European Conference on Power Electronics and Applications, pp.1-7, Sept. 2007.

[17] José Rodríguez, Jorge Pontt, César A. Silva, Pablo Correa, Pablo Lezana, Patricio Cortés, Ulrich Ammann, "Predictive Current Control of a Voltage Source Inverter," IEEE Trans. Ind. Electron., vol.54, no.1, pp.495-503, Feb. 2007.

[18] Bruno Exposto, Helder Carneiro, Carlos Couto, João L. Afonso, "Simulations of a Current-Source Shunt Active Power Filter with Carrier- Based PWM and Periodic Sampling Modulation Techniques," EPE European Conference on Power Electronics and Applications, Birmingham - United Kingdom, pp.1-8, Aug. 2011. 